\title{
Statyba
}

\section{THE ANALYSIS OF UNFIXED BALANCE IN THERMAL EXCHANGE}

\section{J. Juodvalkis PhD , E. Blaževičius PhD \& R. A. Vipartas}

To cite this article: J. Juodvalkis PhD , E. Blaževičius PhD \& R. A. Vipartas (2000) THE ANALYSIS OF UNFIXED BALANCE IN THERMAL EXCHANGE, Statyba, 6:1, 32-38, DOI: 10.1080/13921525.2000.10531561

To link to this article: https://doi.org/10.1080/13921525.2000.10531561

曲 Published online: 26 Jul 2012.

Submit your article to this journal $\pi$

山 Article views: 50

4 Citing articles: 1 View citing articles 둔 


\title{
NESTACIONARIŲ ŠILUMOS MAINŲ PASTATUOSE BALANSO ANALIZĖ
}

\author{
J. Juodvalkis, E. Blaževičius, R. A. Vipartas
}

\section{Ivadas}

Praktiniuose pastatų energetinio ivertinimo skaičiavimuose laikoma, kad pastato silumos mainu su aplinka kiekybinius santykius lemia tik atitvariniq pastato konstrukcijų šiluminè varža.

Pageidaujama temperatūra patalpose gaunama, kai išyla ne tik sildymo prietaisai, bet ir pastato konstrukcijos bei patalpose esantys kiti objektai, t. y. kai tam tikrą šilumos kieki akumuliuoja pats pastatas. Pasikeitus lauko oro arba sildymo prietaisu temperatürai, kinta ir pastato konstrukciju ir vidaus objektı̨ temperatūros, t. y. šiluma patalpos viduje migruoja. Nuo šios šilumos migracijos priklauso, kaip intensyviai šiluma atiduodama ị aplinką.

Šiame straipsnyje kalbama apie tai, ar racionaliai panaudojama pastatų šiluminé inercija. Žinoma, kad reguliuojant oro temperatürą patalpose pagal sudarytus paros, savaitès, sezono temperatūrinius grafikus galima sutaupyti iki $20 \%$ energijos, reikalingos pastatams šildyti, palyginti su pastovios patalpu oro temperatūros palaikymo atveju. Šilumą galima taupyti didinant atitvaru šiluminę varžą arba irengiant siluminio režimo valdymo sistemas. Apciuopiamu šlumos taupymo rezultatı galima pasiekti tik tinkamai suderinus pastaty konstrukcinius sprendimus su šldymo sistemy tipais ir galia, ivertinant nestacionarini silumos mainų pobūdị.

Ypatingą dèmesị tektų atkreipti $\mathfrak{i}$ pramoninius pastatus, kuriu tolesnè eksploatacija nepakeitus esminiu energetiniu charakteristikų neapsimoka.

Rengiant pastatu renovacijos projektus reikia atlikti visapusišką energetiniu pastato savybių analizę ir parinkti optimalu projekto variantą.

Šiuo metu pastatų renovacijos tendencija yra vienpusiška - didinama atitvarinių konstrukciju siluminè varža, bet neatsižvelgiama i patalpu temperatūros reguliavimo galimybes.

\section{Metodika}

Siūlomoji metodika pastatą nagrinèja kaip heterogenini kūną, kurio $\infty>B i>0$. Šilumos mainams tarp sio kūno elementu ir aplinkos imamos 3-ios rūłies ribinès salygos. Pastato Silumos balanso lygtis gali būti diferencialinè:

$$
\begin{aligned}
& \frac{d T}{d \tau}+\mu_{s} \frac{d \vartheta}{d \tau}+\mu_{1} \frac{d t_{1}}{d \tau}+\ldots+\mu_{n} \frac{d t}{d \tau}+ \\
& +m_{a} T+m_{1} t_{1}+\ldots+m_{n} t_{n}=k,
\end{aligned}
$$

čia $T$ - apibendrinta silumos šaltinio temperatūra, $\mathrm{K} ; \vartheta$ patalpos oro apibendrinta temperatüra, $\mathrm{K} ; t_{1}, \ldots, t_{n}-$ pastato atitvariniu elementu (sienu, duru, langu ir $t \mathrm{t}$.) apibendrintos temperatūros, $\mathrm{K} ; \mu$ - dydis, rodantis, kuria akumuliuotos silumos dali sudaro kiekvienas nagrinèjamas kūnas (pastato elementas) silumą atiduodančio kūno (Šilumos saltinio) atžvilgiu, esant vieno laipsnio temperatūru skirtumui, t. y. kūno silumines inercijos rodiklis (bevardis ,masyvumas“); $m_{a}$ - šilumos šaltinio aušimo greitis, $1 / \mathrm{s} ; m_{1}, \ldots, m_{n}-$ šilumos šaltinio aušimo greitis, jei jo silumos atidavimo intensyvumas būtu lygus nagrinèjamo kūno šilumos atidavimo intensyvumui, $1 / \mathrm{s} ; k-$ Šilumos šaltinio kaitimo intensyvumas, $K / \mathrm{s} ; \tau$ - laikas, $\mathrm{s}$.

Šios balanso lygties sprendimo rezultatas yra kiekvieno heterogeninio kūno elemento temperatūros kitimo dèsnio nustatymas:

$$
T=f_{a}(\tau) ; \vartheta=f_{s}(\tau) ; t_{1}=f_{1}(\tau) ; t_{n}=f_{n}(\tau) .
$$

Šio uždavinio sprendimas buvo suformuluotas remiantis [1-7].

Heterogeninio kūno, susidedančio iš baigtinio elementı skaiciaus, komponentus galima sugrupuoti $\mathfrak{i}$ tris pagrindines grupes: šilumos šaltinis (šildymo sistema), vidaus konstrukcijos bei vidaus iranga ir atitvarines konstrukcijos. Pastato nevienalytes atitvarines konstrukcijas, susidedančias iš baigtinio elementy skaiciaus, pagal žinomą metodiką galima pakeisti ekvivalentiniu vienalyciu 
kūnu, turinciu, kaip matyti iš lygybès, ekvivalentines silumines savybes:

$$
\bar{\alpha} F(\vartheta-t)=\sum \bar{\alpha}_{i n} F_{i}\left(\vartheta-t_{i}\right), i=1, \ldots, n,
$$

kur

$$
t=\frac{\sum V_{i} \rho_{i} c_{i} t_{i}}{\sum V_{i} \rho_{i} c_{i}}, i=1, \ldots, n,
$$

čia $\bar{\alpha}$ - redukuotos šilumos atidavimo koeficientas; $F$ konstrukcijos, elemento, šildymo prietaiso plotas, per kuri vyksta šilumos mainai, $\mathrm{m}^{2} ; t$ - apibendrinta išoriniu pastato atitvary temperatūra $\mathrm{K} ; V_{i} \rho_{i} c_{i}$ - atskiru išrinès pastato sienos elementu entalpija, $\mathrm{kJ} / \mathrm{K} ; t_{i}$ - apibendrinto kiekvieno išorès pastato sienos elemento temperatūra, $\mathrm{K}$.

Tuomet pastato šilumos balanso lygti galima išreikšti lygcių sistema:

$$
\left\{\begin{array}{l}
\frac{d T}{d \tau}=k-m_{a}(T-\vartheta) \\
\frac{d \vartheta}{d \tau}=\frac{1}{\mu_{s}}\left[m_{a}(T-\vartheta)-\mu_{1} m_{1}(\vartheta-t)\right] \\
\frac{d t}{d \tau}=m_{1}(\vartheta-t)-m_{i l}\left(t-t_{o}\right) \\
t_{o}=U \sin \frac{\pi}{v} \tau .
\end{array}\right.
$$

Pastato nestacionariu silumos mainu balansinèje lygčiu sistemoje yra îvertinti šie veiksniai:

- šilumos šaltinio galia, jo šilumos talpa, šilumos atidavimo intensyvumas;

- pastato vidaus konstrukciju (vidaus irangos bei pertvaru), vidaus oro silumos imlumas, silumos mainu intensyvumas;

- pastato išorès atitvaru šiluminè varža, šilumos imlumas, silumos mainy su lauko oru intensyvumas.

Isssprendus sią lygčiu sistemą, galima nustatyti šiuos parametrus:

- kokia šildymo sistema yra tinkamiausia energetiniu požiūriu (orinè, vandens, akumuliacinè ir pan.);

- kokios patalpy oro temperatūros reguliavimo galimybès;

- kokia optimali šilumos šaltinio galia;

- koks turi būti šilumos šaltinio darbo režimas;

- kokią itaką pastato siluminiam režimui ir energijos sąnaudoms turi vienokios arba kitokios statybiniy konstrukcijų medžiagos;

- kokią itaką pastato energetinei charakteristikai turi sluoksniu išdèstymo tvarka atitvarose, silumos atidavimo ị aplinką intensyvumas - vèjo itaka.

\section{Pastatų šlumos balanso analizé}

\subsection{Patalpu Šiluminio komforto ivertinimas}

Gamybinese, visuomenines paskirties bei gyvenamosiose patalpose oro temperatūra yra reglamentuojama normatyviniais dokumentais. Tačiau dažnai leidžiama keisti vidaus oro temperatūra per parą, savaitę, sezoną. Iš patirties žinome, kad staigus oro temperatūros pakeitimas patalpose be papildomц energijos sq̨audu yra neimanomas. Ši metodika leidžia tiksliai nustatyti, kokiu greičiu vyksta oro temperatūros svyravimai patalpose, reguliuojant šilumos šaltinio darbo režima.

Pastato isilimo ir ausimo greitis

$$
m=\frac{\bar{\alpha}_{i \bar{s}} F}{\sum V_{i} \rho_{i} c_{i}} 1 / \text { sek }
$$

nepriklauso nuo šaltinio galios. Dydis $\bar{\alpha}_{i s} F \quad \mathrm{~W} / \mathrm{K}$ reiškia pastato šilumos nuostolius, tenkančius vienam laipsniui temperatūru skirtumo; $\sum V_{i} \rho_{i} c_{i}$ - pastato entalpija, $\mathrm{J} / \mathrm{K}$. Kadangi pastatų šiluminè varža yra reglamentuojama normatyviniais dokumentais, tai dydis $\bar{\alpha}_{i . \bar{s}} F$ gali būti mažinamas. Norint keisti vadinamają „šluminę inercija“, tenka operuoti dydžiu $\sum V_{i} \rho_{i} c_{i}$-pastato entalpija.

Kuo didesnis pastato šilimo ir aušimo greitis, t. y. kuo lengvesnès pastato konstrukcijos, tuo pastato siluminis režimas bus lengviau reguliuojamas.

1 pav. pateiktas patalpoje pageidautinos temperatūros grafikas ( $\mathrm{a}$ b c d e f) ir faktinès temperatūros kreivè $\vartheta=f(\tau)$. Užbrūkšniuoti plotai, rodo, kiek patalpos temperatūra nukrypsta nuo pageidautinu sąlygu per para. $\mathrm{Pa}$ talpos oro temperatūros reikšmès, esančios virš pageidautinos temperatūros grafiko, rodo patalpos perkaitinima o esančios žemiau Sio grafiko - patalpos neprišildymą. Nurodyta patalpos temperatūra būna tik tam tikrais momentais (taškai $1,2,3,4$ ).

Grafike pavaizduotos pageidautinos temperatūros laužtines linijos ( $\mathrm{a} b \mathrm{c} d \mathrm{e}$ ) ir išorés oro temperatüros linijos $t_{s k}$ apribotas plotas yra proporcingas skaiciuotiniems patalpos silumos nuostoliams. Faktinè temperatüros kitimo kreivè $\vartheta=f(\tau)$ su abscise $t_{s k}$ apriboja plota $S_{g}$, proporcingą faktiniams šilumos nuostoliams. Ši kreive yra sudarytu diferencialinių lygčiu sprendimo rezultatas atitinkamomis ribinemis sąlygomis. Jei plotas

$$
\left.S_{g}\right\rangle \int_{0}^{24} \vartheta d \tau, \quad \mathrm{Kh},
$$

tai patalpa per parą yra neprišildoma. Jei plotas 


$$
S_{g}\left\langle\int_{0}^{24} \vartheta d \tau, \quad \mathrm{Kh},\right.
$$

tai patalpa yra perkaitinta.

Iš perkaitinimo, ir neprišildymo atvejais nukrypstama nuo pageidautinų terminio komforto salygu. 1 pav. užbrükšniuoti plotai tarp pageidautino grafiko linijos ir faktinès oro temperatūros kreivès bus proporcingi neoptimaliai komforto požiūriu panaudotam silumos kiekiui. Santykis

$$
\eta=\frac{S_{g}}{S_{g}+S_{d}}
$$

apibūdins nukrypimą nuo komfortiniu sąlygų.

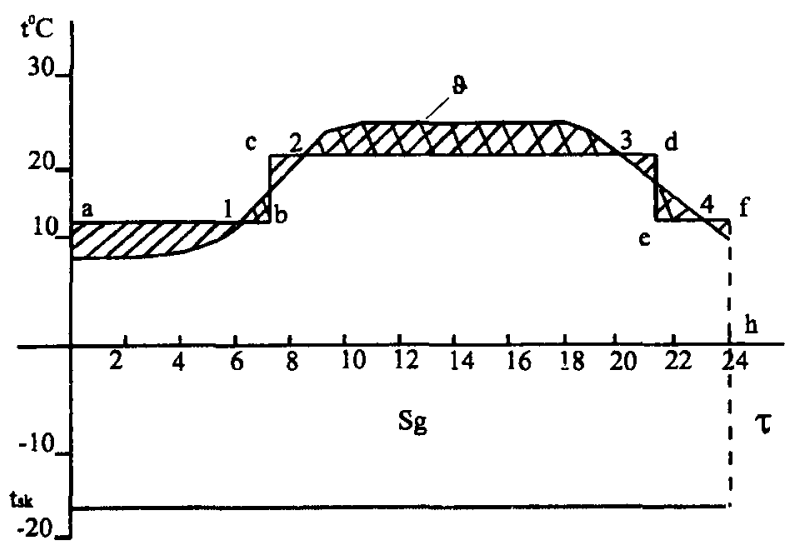

1 pav. Patalpu oro temperatūros grafikas, esant nustatytam patalpц temperatūros režimui

Fig 1. Temperature chart of air in premises of suggested thermal regime

Patalpos perkaitinimui sunaudota šiluma per parą:

$$
Q_{p}=\frac{\bar{\alpha}_{v} \cdot \bar{\alpha}_{i s}}{\bar{\alpha}_{v}+\bar{\alpha}_{i s}} \cdot \frac{F S_{p}}{1000} \quad \mathrm{kWh} .
$$

Šilumos deficitas patalpose:

$$
Q_{n}=\frac{\bar{\alpha}_{v} \cdot \bar{\alpha}_{i \check{s}}}{\bar{\alpha}_{v}+\bar{\alpha}_{i \check{s}}} \cdot \frac{F S_{n}}{1000} \quad \mathrm{kWh}
$$

Bendras neracionaliai panaudotos šilumos kiekis:

$$
Q_{d}=Q_{p}+Q_{n}, \quad \mathrm{kWh}
$$

\subsection{Vejo poveikio ir infiltruojamo oro ịvertinimas}

Labai dažnai kyla klausimas, kaip ịvertinti vèjo ịtaką pastatų Siluminiam režimui. Vejjuotu oru pastebimai pasikeicia šilumos atidavimo koeficientas nuo atitvarų išorès išoriniu paviršu (gali padidèti keliariopai) ir padideja oro infiltracija i patalpas. Kriterijaus dydis $B i$ padideja, kartu pasikeičia ir pastato šilimo ir aušimo greitis $m$ - lemiantis veiksnys nestacionariu silumos mainų procese. Siūlomas nestacionarių šlumos mainu pastatuose skaiciavimo metodas leidžia tiksliai ịvertinti vejo ịtakos absoliutinị dydị t. y. šilumos nuostolių pasikeitimą.

Jei šilumos režimas yra stacionarus, tai galia, kurios reikia infiltruojamam orui pašildyti, nustatoma pagal žinomą išraišką:

$$
N_{i}=\frac{1000}{3600} n_{i} V_{o} \rho_{o} c_{o}\left(\vartheta-t_{o}\right) W .
$$

Jei šilumos mainų režimas yra kintamas, tai infiltruojamam orui pašildyti reikalinga galia yra kintamasis dydis. Todèl šilumos balanso lygtis gali būti išreiškiama diferencialine forma:

$$
d Q_{i}=\frac{1000}{3600} n_{i} V_{o} \rho_{o} c_{o}\left(\vartheta-t_{o}\right) d \tau J .
$$

Bet kuriuo nagrinejjamu momentu infiltruojamam orui pašildyti reikalinga galia yra išreiškiama:

$$
\frac{d Q_{i}}{d \tau}=N_{i}=\frac{1000}{3600} n_{i} V_{o} \rho_{o} c_{o}\left(\vartheta-t_{o}\right) W
$$

čia $N_{i}$-galia, kurios reikia infiltruotam orui pašildyti, W; $n_{i}$ - oro pasikeitimo patalpoje dažnis, $1 / \mathrm{h} ; n_{i} V_{o}-$ infiltruoto oro türis, $\mathrm{m}^{3} / \mathrm{h} ; \rho_{o}$ - infiltruoto oro tūrinè masè, $\mathrm{kg} / \mathrm{m}^{3} ; c_{o}$ - infiltruoto oro specifinè šiluma, $\mathrm{J} / \mathrm{kgK}$; $\vartheta$ - patalpos oro apibendrinta temperatūra, $\mathrm{K}\left({ }^{\circ} \mathrm{C}\right) ; t_{o}-$ išorès oro temperatūra, $\mathrm{K}\left({ }^{\circ} \mathrm{C}\right)$.

Bendruoju atveju ir vidaus oro temperatūra $\vartheta$, ir lauko oro temperatūra $t_{o}$ yra nepastovios. Kintamasis dydis yra ir infiltruojamo oro pasikeitimų skaixius per valandą $n_{i}$.

Energijos sąnaudos infiltruojamam orui pašildyti tam tikram laiko tarpui gali būti apskaixiuojamos pagal išraišką:

$$
Q_{i}=V_{o} \rho_{o} c_{o} \int_{o}^{\tau} n_{i}\left(\vartheta-t_{o}\right) d \tau \mathrm{kJ},
$$

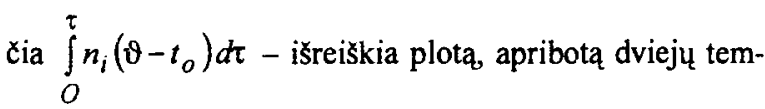
peratūrų kreivèmis, $K h$.

Vertinant pasikeitusi šilumos atidavimo koeficientą ir padidejusią oro infiltracija vejjuotu oru, energijos sąnaudos pastatui (patalpai) šildyti nustatomos iš šios išraiškos:

$Q_{s}=Q_{n}+Q_{i}=N \sum \Delta \tau+\frac{V_{o} \rho_{o} c_{o}}{3600} \int_{0}^{\tau} n_{i}\left(\vartheta-t_{o}\right) d \tau \mathrm{kWh}$. 


\section{3. Šilumos \altinio galios įtaka energijos sąnaudoms, skirtoms pastatui šildyti}

Kūnų šlimo ir aušmo greitis $m$ nepriklauso nuo šilumos Šaltinio galios, jei šilumos mainų režimas yra reguliarus. Kūno šilimo greitis proporcingas šilumos šaltinio galiai, kai šiluma neatiduodama nuo kūno paviršiaus, o kūno aušimo greitis nuo šilumos saltinio galios jau nebepriklauso, t. y. kūno aušimo greitis $d t / d \tau$ yra proporcingas temperatūry skirtumui tarp apibendrintos kūno ir aplinkos temperatūru. Iš esmés pastato išildymo ir aušimo procesas gali būti kontroliuojamas tik per pašildymo fazę, t. y. pastatų (patalpu) terminis komfortas gali būti reglamentuojamas tik per silumos šaltinio galią.

Iš pirmo žvilgsnio paradoksaliai atrodo, kad, didinant Silumos šaltinio galią, energijos sąnaudos patalpoms ¡̧̌šildyti iki norimos temperatūros mažèja.

Jei šilumos šaltinio galia $N_{1} \mathrm{KW}$, tai kūno (pastato) apibendrinta temperatūra $T_{1}$ kyla pagal dèsni:

$$
T_{1}=\frac{k_{1}}{m}[1-\exp (-m \tau)], \mathrm{K},
$$

jei šilumos šaltinio galia $N_{2} \mathrm{~kW}$, tuomet:

$$
T_{2}=\frac{k_{2}}{m}[1-\exp (-m \tau)], \mathrm{K} .
$$

Šildant iki tos pacios temperatūros $T_{1}=T_{2}$ :

$$
\frac{k_{1}}{m}\left[1-\exp \left(-m \tau_{1}\right)\right]=\frac{k_{2}}{m}\left[1-\exp \left(-m \tau_{2}\right)\right] .
$$

Jei şilumos šaltinio galia $N_{2}$, tai kūno j̧šilimo trukmé:

$$
\tau_{2}=\frac{1}{m} \ln \frac{1}{1-\frac{N_{1}}{N_{2}}\left[1-\exp \left(-m \tau_{1}\right)\right]} \text { h. }
$$

Pirmuoju atveju energijos kiekis, sunaudotas kūnui ¡šildyti:

$$
E_{1}=N_{1} \tau_{1} \mathrm{kWh},
$$

antruoju:

$$
E_{2}=N_{2} \tau_{2} \mathrm{kWh}
$$

Pavyzdys. Kaitinamas künas, kurio $m=1 \frac{1}{h}$, pirmuoju atveju naudojant silumos saltini $N_{1}=1 \mathrm{~kW}$, antruoju atveju $-N_{2}=2 \mathrm{~kW}$. Per $1 \mathrm{~h}$ pirmuoju atveju künas ¡kais iki tam tikros temperatüros, o antruoju atveju iki tos pacios temperatūros iłsils per:

$$
\tau_{2}=\frac{1}{1} \ln \frac{1}{1-\frac{1}{2}[1-\exp (-1)]}=0,38 \mathrm{~h} .
$$

Pirmuoju atveju energijos bus sunaudota:

$$
E_{1}=1 \cdot 1=1 \mathrm{kWh} \text {, }
$$

antruoju:

$$
E_{2}=2 \cdot 0,38=0,76 \mathrm{kWh} .
$$

Ekonomiškesnis yra kūno (pastato) sildymas galingesniu šilumos saltiniu. Tai paaiškinama tuo, kad šildomas kūnas (pastatas) per trumpesni šildymo laiko tarpa mažiau energijos atiduoda i aplinka. Todèl galima konstatuoti, kad, esant nestacionariam silumos mainų režimui pastate, šilumos šaltinio optimalios galios nustatymas yra labai svarbus veiksnys energijos taupymo požiūiu.

Kita vertus, patalpu terminis komfortas būtu geresnis, jei pavyktu pagreitinti patalpu ausima. Taxiau šam procesui reikia papildomu energijos sqnaudu, t. y. patalpu oras turètu būti papildomai aušinamas, norint sumažinti oro temperatūrą.

Jei paanalizuosime pirmaja lygti is (5) lygciu sistemos:

$$
\frac{d T}{d \tau}=k-m_{a}(T-\vartheta)
$$

tai konstanta $k$, nusakanti silumos saltinio kaitimo greiti gali turèti ir neigiamą reikšmę, t. y. šilumos šaltinis pastato aušimo metu gali ir ,sugerti“ silumą. Tai reikštu, kad patalpa turètų būti aušinama $(T<\vartheta)$. Tokiu atveju patalpos oro temperatūros kritimas gali būti pagreitintas dirbtinai. Siuo atveju turètú būti irrengta šaldymo iranga.

Taciau kyla klausimas, ar panaudota energija termodinaminiame šaldymo masinos cikle nebus didesnè už gautą energijos ekonomija, priartinant patalpos oro temperatürą prie pageidautinos. Šio uždavinio sprendimui reikia atskiro detalaus nagrinejjimo bei ekonominès analizès.

\subsection{Konstrukcinių sprendimy itaka pastato energeti- nei charakteristikai (apšiltinimo variantas)}

Pagrindiniu pastato siluminès charakteristikos kriterijumi yra laikoma atitvarinių konstrukcijų šiluminè varža. Projektuojant pastatų išorines atitvaras bei parenkant medžiagas vidaus konstrukcijoms, per mažai dèmesio skiriama jų masyvumui bei sluoksnių išdestymo tvarkai atitvarose. Dažnai diskutuojama, kur tikslingiau ịrengti silti- 
nantị sluoksni - atitvaros vidaus ar išorès puseje. Nèra jokio skirtumo, jei skaiciuojama stacionarinemis silumos perdavimo salygomis. Taciau, ivertinus tai, kad pastatuose faktiškai šilumos balansas yra kintamas, atitvaru masyvumo veiksnys igyja didelę reikšmę. Irengiant šiluminio režimo vaidymo sistemas, tai būtina įvertinti. Siūloma metodika leidžia parinkti optimalius konstrukcinius pastato sprendimus ir tinkamas šildymo sistemas.

\subsubsection{Pastato vidiniu konstrukcijy ir vidaus irangos masyvumo itaka vidaus oro temperatúros reguliavimo lankstumui}

Konkrečiu pastatų kintamo šluminio režimo tyrimai rodo, kad patalpose palaikant lankstụ temperatūrų režimą per para labai svarbu yra pastato vidiniu konstrukcijų bei vidaus irangos masyvumas. Kuo didesni silumos kiekiai akumuliuojami pastato viduje, tuo lèciau keiciasi patalpos oro temperatūra, o tai reiškia, kad energijos ekonomija reguliuojant vidaus oro temperatürą yra sunkiau gaunama.

a)

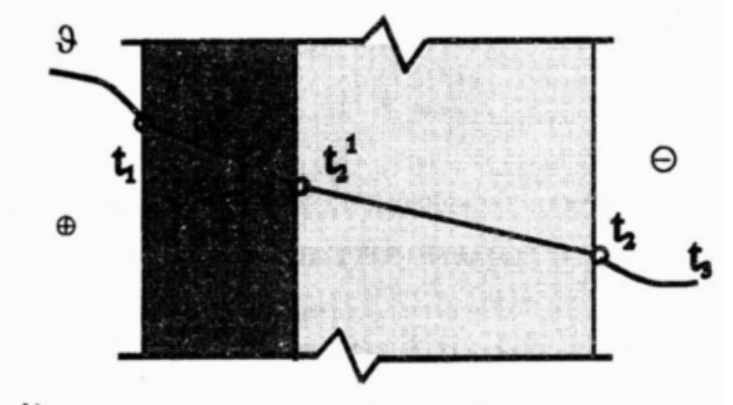

b)

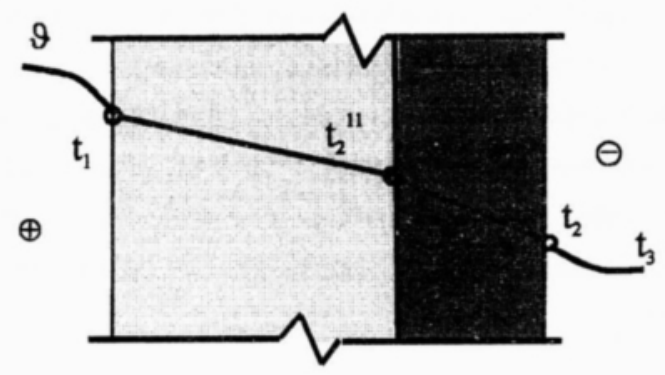

2 pav. Pastato masyvios išorès atitvaros siltinimo variantai

Fig 2. Position of insulating layer for massive external wall

Panagrinekime ribini atveji kai vidaus konstrukcijose akumuliuotos šlumos kiekis yra nežymus. Šiuo atveju bevardè vidaus konstrukciju silumos talpa $\mu_{s} \rightarrow 0$. Tokiam pastatui kintamo silumos balanso lygciu sistema (5) bus tokia:

$$
\left\{\begin{array}{l}
\frac{d T}{d \tau}=k-m_{a}(T-\vartheta) \\
\vartheta \equiv \frac{m_{a} T+\mu_{1} m t_{1}}{m_{a}+\eta_{1} m_{1}} \\
\frac{d t_{1}}{d \tau}=m_{1}(\vartheta-t)-m_{i l}\left(t-t_{o}\right) \\
t_{o}=U \sin \frac{\pi}{v} \tau .
\end{array}\right.
$$

Antroji šios lygčiu sistemos lygtis rodo, kad vidaus oro temperatūros kaita priklauso tik nuo silumos saltinio ir pastato atitvaru apibendrintų temperatüru $T$ ir $t_{1}$ kitimo désnių. Jei atitvaru vidaus konstrukcijose (irangoje) yra akumuliuotos šlumos, tai patalpos oro temperatūra bus lengviau reguliuojama ir bus gaunama didesnè energijos ekonomija, palyginti su tokiu paciu pastatu, turinciu masyvias vidaus konstrukcijas (masyvia iranga).

\subsubsection{Pastaty išorinių atitvarų konstrukcinių sprendimų itaka pastato కiluminio režimo reguliavimo lankstumui}

Iš patyrimo žinome, kad masyvių išrès atitvaru pastatai daug ilgiau išlaiko silumą negu lengvu konstrukciju statiniai, turintys tạ pacią atitvaru siluminę varžą. Jei pastate yra palaikomas sąlygiskai pastovus šluminis režimas, tai pastato išoriniu sienu konstrukciniai sprendimai praktiskai neturi itakos energijos sąnaudoms, skirtoms šildymui. Tačiau jei norima patalpose palaikyti kintamą oro temperatūrą ir taupyti energijos sanaudas sildymui, tai būtina ivertinti pastato galimybes, prisitaikyti prie pageidaujamo vidaus oro temperatūrų kaitos grafiko. Svarbu atsižvelgti $\mathfrak{i}$ išorès atitvarų konstrukciją. Tai galima pailiustruoti žemiau pateiktu pavyzdžiu. Teoriškai buvo išnagrinèti konkretaus pastato keli renovacijos variantai. Palyginimui pateikiami pastato su tokiu pačiu izoliaciniu sluoksniu du konstrukciniai variantai: 1 - apšiltinto iš lauko; 2 - apšiltinto iš vidaus.

Irengus patalpu oro temperatūros valdymo sistema gaunama energijos ekonomija pastatui šildyti (lyginant su nereguliuojamo temperatūros režimo variantu) sudaro: pirmuoju atveju - $(6,5-7,6) \%$; antruoju atveju $-(3,8-4,8) \%$.

Šie rezultatai rodo, kad energetiniu požiūriu efektyvesnis yra pirmasis pastato variantas - kai jis apšiltinamas iš vidaus. Tai galima paaiß̌kinti ir క̌ia paprasta iliustracija: masyvi išores pastato atitvara apšiltinama vienodo storio izioliacijos sluoksniu iš vidaus ( 2 a pav.) ir iš lauko ( 2 b pav.) pusès. 
Sluoksnių paviršių temperatūros pavaizduotos esant nusistovèjusiam režimui. Pirmuoju atveju, kai šilumos izoliacija yra iš lauko, sienoje akumuliuotos šilumos kiekis išreiškiamas šia lygybe:

$$
\begin{aligned}
& q_{a k}^{1}=V_{i} \rho_{i} c_{i}\left(\frac{t_{1}+t_{2}^{1}}{2}-t_{0}\right)+ \\
& +V_{m} \rho_{m} c_{m}\left(\frac{t_{2}^{1}+t_{3}}{2}-t_{0}\right) \mathrm{kJ} .
\end{aligned}
$$

Antruoju atveju, kai క̌lumos izoliacija iš vidaus, sienoje akumuliuotos šilumos kiekis išreiškiamas šia lygybe:

$$
\begin{aligned}
& q_{a k}^{11}=V_{m} \rho_{m} c_{m}\left(\frac{t_{1}+t_{2}^{11}}{2}-t_{0}\right)+ \\
& +V_{i} \rho_{i} c_{i}\left(\frac{t_{2}^{11}+t_{3}}{2}-t_{0}\right) \mathrm{kJ} .
\end{aligned}
$$

Jei išorinès sienos yra masyvios, o izoliacinis sluoksnis turi didelę šiluminę varžą ir yra nedidelès masès, tai akivaizdu, kad antruoju atveju atitvaroje akumuliuotos šilumos kiekis yra didesnis negu pirmuoju:

$$
q_{a k}^{1}>q_{a k}^{11}
$$

Aišku, kad, esant tai pačiai atitvaros šiluminei varžai, atitvaroje akumuliuotos šilumos atidavimas i išorę antruoju atveju užtruks ilgiau negu pirmuoju. Tai reiškia, kad patalpos aušmas bus lètesnis, ir norima temperatūra joje bus pasiekiama lèčiau. Jeigu neimanoma patalpoje greiciau pasiekti pageidaujamos oro temperatūros, energijos taupymo galimybès šldymui mažèja.

\section{Išvados}

1. Pasiūlyta pastatų nestacionarių šilumos mainų režimu skaičiavimo metodika taikytina kompleissiniam naujai projektuojamy ir renovuojamu pastatu energetiniam vertinimui.

2. Galima sudaryti kiekvieno pastato (kiekvieno pastato renovacijos varianto) šilumos balanso lygti diferencialine forma. Sudaryta lygxiu sistema (5) apima visa informaciją apie pastato silumines savybes. Atitinkamomis ribinemis salygomis galima nustatyti pastato energetinius parametrus.

3. Siülomos metodikos pagrindu galima nustatyti energetiniu požiüriu optimalu pastato statybos arba reno- vacijos varianta, kompleksiškai ịvertinant atitvarų struktūros bei patalpu oro temperatüros valdymo (reguliavimo) irangos efektyvuma.

4. Apšiltinant masyvų pastata is lauko pusès, labai sumažejja patalpu oro temperatūros valdymo (reguliavimo) galimybès, taip pat ir energetinis efektyvumas, esant tiems patiems šilumos nuostoliams.

5. Silumos šaltinio galia bei tipas turi būti nustatoma optimizuojant kapitalinių idejinių ir eksploatacinių iłlaidų santyki.

\section{Literatūra}

1. В. И. Богословский. Строительная теплофизика. М: Высшая школа, 1982.415 с.

2. Г. Гребер, С. Эрк, У. Григуль. Основы учения о теплообмене / Пер. с немецкого. М.: Иностранная литература, $1958.566 \mathrm{c}$.

3. И. Ф. Жеребятьев, А.Г. Лукьянов. Математическое моделирование уравнений типа теплопроводимости с разрывными коэффициентами. М.: Энергия, 1968. $56 \mathrm{c.}$

4. Ф. М. Камья. Импульсная теория теплопроводимости / Пер. с французского. М.: Энергия, 1954. 286 с.

5. К. Ф. Фокин. Строительная теплотехника ограждающих частей здания. М.: Стройиздат, 1973. $287 \mathrm{c}$.

6. J. Juodvalkis. Nestacionariniu šlumos mainų pastatuose skaiciavimo metodika ir eksperimentinis patikrinimas: Techn. m. k. disertacija. K., 1992.67 p.

7. J. Juodvalkis, R. A. Vipartas. Šiluminio režimo valdymas pastatuose // Energetika, 1997, Nr. 1, p. 48-51.

Iteikta 19990910

\section{THE ANALYSIS OF UNFIXED BALANCE IN THERMAL EXCHANGE}

\section{J. Juodvalkis, E. Blaževičius, R. A. Vipartas}

Summary

Today the tendency of building renovation is one-sided, ie thermal resistivity of enclosure constructions is being increased ignoring the temperature control possibilities in flats. Appreciable heat savings may be achieved solely through a duly coordination of the constructive building solutions with the type and power of heating systems and by the evaluation of an unfixed character of heat exchange.

In the proposed method a building is treated as a heterogeneous body $(\infty>B i>0)$. The conditions of the 3 rd rate are accepted for the heat exchange between the elements of this body and the surroundings (1). The result of the equation solution is the determination of temperature alteration law in each element of a heterogeneous body (2). The non-monolithic enclosure constructions having a final number of elements may be changed by an equivalent monolithic body with equivalent thermal properties $(3 ; 4)$.

The following factors in the unfixed heat exchange balance system of equations have been taken into consideration:

- the power of a heat source, its thermal capacity, the intensivity of heat delivery; 
- the receptivity of interior constructions of a building (its equipment and partitions) and of inner air, the intensity of heat exchange;

- thermal resistivity of exterior enclosures of a building heat receptivity, the intensity of heat exchange with the outside air

The solutions of this equation system gives the following parameters:

- the optimal thermal comfort for a particular building;

- the most suitable heating system from the point of view of energy;

- control possibilities of the inner temperature in a building;

- the optimal power of a heat source and the effect of the energy expenditure caused by the heating of a building;

- working conditions of a heating source;

- the rate of outside temperature fluctuation under control of the working conditions of a heating source;

- the effect of different materials on the working conditions of a building and on energy expenditure in building constructions;

- the effect on building energetic characteristics of the order of layer distribution in exterior enclosures as well as the intensivity of heat delivery in the environment (wind effect).
Jonas JUODVALKIS. PhD. Head of the Laboratory ot Heating Systems. Institute of Architecture and Construction. Tunelio 60, LT-3035 Kaunas, Lithuania.

Doctor (1992). Author of 39 papers, 5 inventions. Research interests: dynamic heat exchange in solid bodies, accumulative heating systems.

Egidijus BLAŽEVIČIUS. PhD. Director of the Institute of Architecture and Construction. Tunelio 60, LT-3035 Kaunas, Lithuania.

Doctor (1986). Author of over 50 publications. Research interests: heat exchange in premises, microclimate of premises, building climatology, alternative heat sources.

Ramanas Albertas VIPARTAS. Research Fellow. Institute of Architecture and Construction. Tunelio 60, LT-3035 Kaunas, Lithuania.

Author of 23 papers, co-author of 4 Lithuanian regulations. Research interests: alternative heating sources accumulative heating systems, building climatology. 